\title{
THE SELECTION OF A MECHANICAL VENTILATOR
}

\section{H BARRIE FATRLEY, M B, B.S.(LOND) F.F.A.R.C S (ENG.) 1}

Mechanical ventilating machines are being used in incriasing numbers for the maintenance of respiration both in the operating room and in the treatment of respiratory insufficiency. On the North American continent and in Europe, the wide selection of avallable machines demands a full appreciation of the pertinent factors when consideration is bemg given to the purchase of such equpment

\section{Ventilatory Adequacy}

The main purpose of all equipment of this type is to produce adequate alveolar ventilation Since $V_{A}=f\left(V_{T}-V_{D}\right)$, variations in anatomical and physiological dead space will influence greatly the tidal volume necessary to achieve satisfactory alveolar ventilation at a given respiratory rate At the start of every stroke, the dead space and the resistance must be overcome and, in consequence, it is advantageous to deliver high stroke volumes at a relatively slow rate This is especially the case where there is an increased dead space (for example, as in emphysema or cases with copious sputum $)^{2}$ and it is felt that intermittent positive pressure (I.P P.) machines should be capable of delivering over $1,000 \mathrm{ml}$ per stroke, in a short period To do this efficiently, delivery rates of $40-601 / \mathrm{min}$ will be required during inspiration (2)

\section{Airway Pressures}

At the end of the inspiratory phase, the peak airway pressure will rise to a level dependent upon the sum of the elastic and non-elastic resistance (3) Cournand and his associates have provided the classical work (4) on optımum airway pressure wave form during the respuratory cycle, using intermittent positive pressure respiration (I P P R ) The aim is to produce the lowest possible mean intrathoracic pressure and this is best achieved by a swift mspiratory phase, an immediate fall in pressure to zero and a pause. Recent investigative work, in many centres, suggests that high velocity inflation may give uneven ventilation and a consequent rise in physiological dead space, particularly in certain pathologies with varying intrapulmonary resistances, for example, emphysema Thus, on such occasions, the ability to lengthen the inspiratory phase may be useful However, in normal circumstances with IPP.R. the expiratory phase and the respiratory pause should, together, be twice as long as the inspiratory phase It is generally agreed that the fall in venous return is minimal, using the Cournand type III wave form, as described above. The efficiency with which certan machines achieve this wave form is discussed by Saklad et al. (5).

1Department of Anaesthesia, Unversity of Toronto and Toronto General Hospital

${ }^{2}$ Recently a patient in the Toronto General Hospital Respiratory Unit (1), with bilateral pneumonia and a bronchopleural fistula, required stroke volumes considerably in excess of $1,000 \mathrm{ml}$ to mantain a normal arterial $\mathrm{pCO}_{2}$ 
Adequate stroke volumes will usually be achieved with pressures of $15-20 \mathrm{~cm}$ $\mathrm{H}_{2} \mathrm{O}$, but the occasional necessary use of higher inflation pressures need not cause great anxiety as this may not be associated with high transalveolar pressures Thus, in many such instances (for example, bronchospasm) much of the positive pressure may be dissipated in traversing a high tracheo-alveolar gradient.

\section{The Negative Phase}

The negative phase is likely to be of definite value on only two occasions. (1) rare instances where the systemic blood pressure falls with I.P.P.R. (occasional cases with hypovolaemia (6)-especially those associated with a low lung-thorax compliance-would fall into this group); (2) occurrences of low lung volumes, for example, following pulmonary resections (7). In both instances, the negative pressure permits increased tidal exchange without high positive pressures. In the second instance this may be the only way of achieving an adequate tidal exchange. It is of note that the increased likelihood of hypovolaemia during major surgery suggests a greater need for the negative phase in machines used in operating rooms, as opposed to those used for treating respiratory insufficiency

The possibility of collapsing weakened bronchioles with negative airway pressures-thus increasing aur trapping-is always present in the emphysematous patient (8). This situation is most easily produced by a rapid swing from positive to negative phase. Thus, if used at all in such cases, it has been suggested that it may be useful to apply a small negative pressure in the latter part of expiration (for example, the last third of the respiratory pause) (9). It has been shown by Opie and his associates that the introduction of a negative phase does not necessarily improve expuratory flow in the emphysematous patient (10).

\section{Types of Machines}

These fall into two broad groups (11) (1) volume constant-pressure variable machmes, (ii) pressure constant-volume varıable machines

\section{Volume Constant-Pressure Variable Machines}

These machines have an obvious advantage in providung a constant predetermined amount of ventilation. In consequence, they are of particular value in patients presenting varying resistances to inflation: in the operating room-for anaesthesia using intermittent intravenous doses of muscle relaxant, thoracic surgery, patients with varyıng degrees of bronchospasm or copious sputum being suctioned intermittently; in the treatment of respiratory insufficiency-the same advantages obtain and it might be noted that there is a special advantage here in the treatment of tetanus and in patients with considerable sputum.

These machines are set to deliver a constant tidal volume and do so in the face of widely varying resistances $(5,11)$. They are usually equipped with an adjustable blow-off valve, which one may set to blow off at whatever is considered to be the maximum safe arway pressure The latter is much higher than is commonly believed and is, perhaps, in the region of $50 \mathrm{~cm} . \mathrm{H}_{2} \mathrm{O}$ in the normal person 
and may be higher in certan pathological states. However, in emphysema the varying intrapulmonary resistances may cause very high transmural pressures to be applied in the region of the more diseased alveol. Thus, in patients with bullae or air cysts, the maximum safe pressure might be lower.

\section{Pressure Constant-Volume Variable Machines}

These machines are set solely to achieve a constant pressure on inflation. They suffer from the disadvantage that, at a given pressure, the tidal volume varies with changes in resistance Thus, at a given airway pressure 'setting, changes in sputum volume and position will vary alveolar ventlation from moment to moment. Differences in elastic resistance from patient to patient (and even in the same patient, for example, with tetanus, intermittent relaxants, etc.) will produce varying alveolar ventalation. Thus, a constant ventilation cannot be ensured with these machines although in many instances it is achievable (for example, in patients with normal lungs having a lower abdominal operation or suffering from barbiturate intoxication, however, even in the latter, changes in posture will cause varying ventilation).

Volume-limiting machines. A few pressure constant machines are fitted with a device which prevents the bellows excursion going beyond a certain adjustable point Thus, by setting the pressure higher than is necessary, the bellows can"be set to deliver only a certain volume This is a variation on the volume constant theme, in effect. However, many of these machines are not fitted with valves and pressure gauges with high enough ranges to permit constant ventilation against high resistance

\section{Motive Force}

Ventılatıng machines are nearly all activated by etther compressed gas ( air, $\mathrm{O}_{2}$, etc.) or an electric motor.

Compressed gas. These machines function either as intermittently opening adjustable reducing valves-the motrve force being also the inflatung gas-or have their own circuit, separate from the motive force The former is used in respiratory therapy and the latter in the operating room These machines have the disadvantage of requiring a large tank of compressed gas (in most instances), unless sufficient line pressure is avallable trom a wall oxygen supply. The cost of compressed air and of oxygen being comparable, there is little to choose between them as a motivating force

Electric motor. Many highly efficient machines run from an electric motor which, of course, must be explosion proof. These machines are either of type $(b)$ or (c) (below).

\section{Machine Circuits}

Most commercially available machines fall into one of three groups: (a) the intermittently opening reducing valve, as mentioned above; $(b)$ the electrically driven piston, drawing in room air and then delivering this to the airway by a system of non-return valves, (c) machines consisting of a rebreathing bag or 
bellows in a chamber. The bag is in contmuity with a crrcuit to the patient and pressure is applied intermittently to its exterior, by blowing air into the chamber. This is the group commonly seen in the operating room.

\section{Additional Features on Certain Machunes}

Although the basic requirement is to maintain adequate alveolar ventılation, certain special features are of some assistance in achievng this end.

\section{Operating Room Machines}

(a) Separate patient circuit Clearly, this is important in the operating room as a means of maintaining anaesthesia.

(b) Flow adaptability Certan machines of this type function most satisfactorily with a specific flow of gases running and are unable to function with very high or very low anaesthetic gas flows Flexubllity in this regard is most important.

(c) Automatic refilling In machune type (c) (above), when the reservorr bag/bellows empties, the pressures applied to its extenior will be ineffectual and this situation may arıse undetected. At least one machine has an automatic device whereby the bag is automatically refilled at thispoint.

(d) Alternative hand ventilation For those of us whose appreciation of the patient's status is largely dependent upon the "feel of the bag" it is important that the manual alternative should be of the type whrh will give us that apprecration. Thus, on some machines the alternative is a concertma and in others an ordınary rebreathing bag

(e) Connections to the patient If this is one straight corrugated rubber tube, which is to be attached to the curcle of an anaesthetic nachine, there will be a considerable length of expansile rubber in the system. One machine can be connected directly to the patient by its own curcle, coataining non-return valves However, this machine, together wath at least one other, requires an absolutely arr-tight circuit to function satisfactorily. Thus, one should examine the means by which one attaches the machine to the patient.

(f) Noise. Occasionally, the noise of these machmes will prove irritating to the surgenn and this factor should be taken into consideration before purchasing

\section{Respiratory Therapy Machines}

(a) Long-term reliability Since these machines sometimes have to run for weeks on end, it is essential that they should not be temperamental It is now an established fact that certain machines have a very satisfactory record in this regard.

(b) Simplicity. Since patients will be left in the care of nurses while entrely dependent on this equipment, it is essential that the nurses should be able to understand their mode of action and how they may be adjusted. Thus, the more complicated machines should probably only be used in special units with a permanent, trained nursing staff ( 1 ). 
(c) Patient-triggering mechanism. Many machines are capable of being activated by the patient although the indications for this are not yet certain. Some machines are bullt purely for this purpose while others can be switched to automatic control, should the patient's initiation become inadequate Yet a third group will switch to automatic control and back again-spontaneously-depending on the patient's respiratory efforts All patient-triggered machines deliver a positive pressure phase in response to the patient's creating a small negative airway pressure This is either set to fire off at, say, $-2 \mathrm{~cm}, \mathrm{H}_{2} \mathrm{O}$ or may be adjustable (down to $05 \mathrm{~cm} \mathrm{H}_{2} \mathrm{O}$ )

(d) A means of monitoring Gross ventilatory deviations from normal may be produced by these machines and therefore a means of measuring tidal volume must be on hand. Thus, there should be some means of passing expired air into a gas or ventilation meter Certain of the machınes, possessing complex expiratory valves of their own, do not readıly lend themselves to this. In others, it is possible to insert a non-return valve near the aurway, thereby collecting expired gas in a meter Certain types of patient-triggered equipment are difficult to monitor as are others with a negatuve phase.

(e) Humidification Adequate humidity in the unspired air is most important in long-term cases. Certain machunes have a humidıfier bult in, but those which do not can be made to deliver their inflating medium through a separate "humıdifyng box" Ideally, this should be thermostatically controlled

(f) Inflating gas. High concentrations of oxygen for prolonged periods being madvisable, most machines can dilute the oxygen with air (usually in set amounts down to 40 per cent $\mathrm{O}_{2}$ ) or will deliver room air alone (to which oxygen may be added).

(g) Warning devices These are fitted to certain of the electrically operated machines and may be a light or a bell They may show either (i) too little pressure (e g, a leak in the circuit or a power fallure) or (ii) too much pressure In the latter instance, this can be used to indicate an increase in arrway resistance. Thus, if it is found that adequate ventilation is achieved with a volume constant machine by a pressure of $x \mathrm{~cm} \mathrm{H}_{2} \mathrm{O}$, then the blow-off valve can be set at $x+5 \mathrm{~cm} \mathrm{H}_{2} \mathrm{O}$ If the warning light is linked to the blow-off valve, then a lobar collapse, collection of secretions, tetanic spasm, etc. will be indicated by its going into action.

\section{All Machines}

(a) Pressures required. Normally, positive pressures in the range $12-20 \mathrm{~cm}$ $\mathrm{H}_{2} \mathrm{O}$ will achieve adequate ventilation (although lower pressures should be avalable if paediatric therapy is contemplated). Positional changes (e g. Trendelenburg) may require this to be increased and occasional cases with a high resistance may require pressures up to $60 \mathrm{~cm} \mathrm{H}_{2} \mathrm{O}$. This is most extreme but may be seen in occasional cases of respiratory insufficiency.

(b) Negative phase Negative pressures up to $-15 \mathrm{~cm} \mathrm{H}_{2} \mathrm{O}$ may be useful on occasion, as mentioned above. They are more frequently of use in machines for operating room use 
(c) Phase ratio variability. The value of varying the duration of the separate phases of respiration has been discussed in many publications and is certainly of occasional use. The advantages of this facility must be set agaiñst the a added complication which the additıonal knobs provide for the attendant staff. In principle, the concept should be "Use the simplest machine which will do the job."

(d) C.S A. approval. On any electrically-operated equipment, this is of course essential and it is of interest that certain excellent and well-proven machines are not available in this country because their electrical equipment is not of the required standard.

(e) Built-in manometer Thus would appear to be an mvaluable accessory which is not avallable on some machines (one-the Morch Piston Respiratorbecause it is designed to run with high flows and an uncuffed tube-possesses neither manometer nor blow-off valve). It is important to realize that neither pressures nor volumes measured at the machine are the same as in the airway itself and, if absolute measurements (as opposed to an indication of a change) are required, they must be carried out at or very near the aurway.

( $f$ ) Built-in spirometer or gas meter This is a feature of volume-controlled machines, ipso facto. However, certam pressure constant machines possess a ventilation meter in the circuit and this is most useful (a reduction in volume indicating an increase in resistance, for any of the reasons mentioned above). It is necessary to check these meters, from tome to time, of course.

(g) Built-in suction This is provided as a part of certain units.

\section{SUMMARY}

(1) An attempt has been made to discuss the elementary physiological requirements of a mechancal ventilator

(2) The types of machine avalable are grouped and it is shown that volume constant-pressure variable machmes provide the most satısfactory ventlation.

(3) The motive forces used and the machine sircuits are described in outline

(4) Special features avallable on (a) operatı.rg room machines and $(b)$ res puratory therapy machines are described

(5) A table is appended, showing certain of the features avalable on many machines

\section{RÉSUMÉ}

La popularité croıssante de respirateurs mécanıques dans les salles d'opérations et dans le traitement de l'insuffisance respuratorre exige une connasssance approfondıe de différents facteurs (1) Ventılation. l'appareil doit pouvoir fournir un volume inspiratoire de plus de $1,000 \mathrm{cc}$ en un temps, au cas où l'on serait en presence d'un espace mort très élevé (2) Pression dans l'arbre respirata re: la courbe, III, de Cournand, est idéale. Elle produit une insufflation rapíle, le retour au zéro de pression est immédıat et suivi d'un sırrêt. La durée de l'expiration et de larrêt doit être le double de celle de l'inspiration. Une pression negative peut être utile en cas d'hypovolémie ou après une résection pulmonaire 


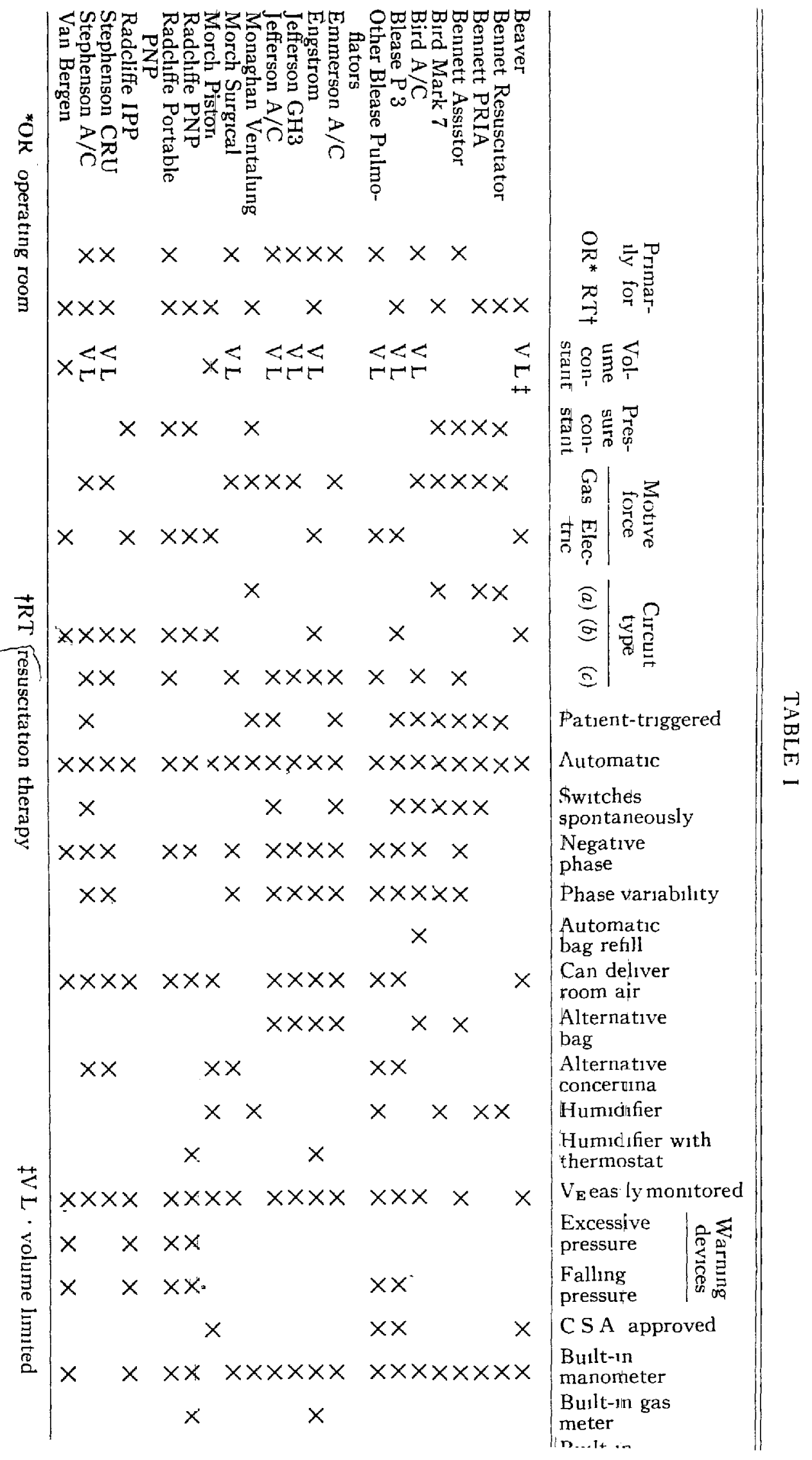


(3) Différents modèles. il exıste des appareıls à volume constant et pression variable et d'autres à pression constante et volume variable. Les premiers fournissent une ventilation constante beaucoup plus facilement. On discute des différents circuits et forces motrices et on mentionne les détails suivants. L'appareil en service dans Ia salle d'óperation doit avoir un circuit dans lequel on peut introduire n'importe quel mélange de gaz anesthésıque. On discute des avantages d'un ballon qui se remplit automatıquement et du besoin d'un appareil supplémentaure de ventilation L'appareil dont on se sert dans le cas de depression respiratoire doit être de constructon robuste, de manipulation facile, avoir un bon humidificateur, et, si possıble, avorr un mécanısme que le patıent peut facilement déclencher luimême Le volume de l'aur courant dott être enregistré faclement. On discute d'autres questions. Le tableau démontre quelques-unes des qualités de certains appareils

\section{REFERENCES}

1 Barber, $\mathrm{H} \mathrm{O}$, et al A Respiratory Unit Canad M A J 81 (July, 1959)

2 PAsk, $\mathrm{E}$ A. The Maintenance of Respiration in Respiratory Paralysis Proc Roy Soc Med 48239 (1955)

3 Nunv, J F Physiological Aspects of Artıficial Ventilation Brit J Anaesth 29540 (1957)

4 Counnand, A, et al Physiological Studies of the Effects of Intermittent Positive Pressure Breathing on Cardiac Output in Man Am J Physiol 152162 (1948)

5 SAKLAD, M., et al Choice of Pressure Breathing Apparatus Factors to Consider Anesth \& Analg 38. 32 (1959)

6 Maloney, J V The Importance of a Negative Pressure Phase in Mechancal Ventilators J A M A 1952212 (1953)

7 Bjonk, $\mathrm{V} \mathrm{O}$, et al The Treatment of Ventilatory Insufficiency after Pulmonary Resection with Tracheostomy and Prolonged Artificial Ventilation J Thorac Surg 30356 (1955)

8. Nunn, J F The Anaesthetust and the Emphysematous Patient Brit J Anaesth 30134 (1958)

9 VAN BERGEN, F H, et al A New Respirator Anesthesiology 17 708 (1956)

10 OpIE, $\mathrm{L} \mathrm{H}$, et al Mechanical Properties of the Qhest during Intermittent Positive Prossure Respuratuon Lancet 1 545 (1959)

11 Elam, J O, et al Performance of Ventulators Effects of Changes in Lung-thorax Compliance Anesthesiology 1956 (1958) 